\title{
194. Effect of Ice Water on the Population Growth of the Water-flea, Moina macrocopa Strauss."
}

\author{
By Arata Terao and Yoshio Inoue. \\ (Comm. by C. Ishikawa, M.I.A., Dec. 12, 1934.)
}

Various authors ${ }^{2)}$ have reported on greater increase in number of organisms in ice water. But, as already demonstrated by Terao and Tanaka," greater size of maximum population of organisms under experimental conditions does not always mean their greater speed of development in the environments under consideration. It appears that an approach to the problem is possible by studying parthenogentic increase of cladocerans in ice water.

Commercial block of ice was melted, and $75 \mathrm{cc}$. of the water thus obtained were mixed with 1 cc. of Ringer's solution, and 1 cc. of "rice water" which was got by washing rice with tap water. This culture medium was freshly made every day and $15 \mathrm{cc}$. of this fluid were put in each of four vials, in which the larvae originated from one mother water-flea, Moina macrocopa, were kept. The control animals consisted of four individuals hatched from the same mother at the same time as the experimental animals and were given daily equal volume of the medium which was prepared by mixing $75 \mathrm{cc}$. of tap water, $1 \mathrm{cc}$. of Ringer's solution, and 1 cc. of rice water. The eight vials thus furnished were put in an incubator which ran at $25.5^{\circ} \mathrm{C}$. We beg to record our indebtedness to the staff of our physical laboratory for the regulation of the apparatus.

As shown in Table 1, the average speed of development was greater in tap water, but the average for the asymptotic populations was higher in ice water. Far from being complete as it is, the present paper may, to a degree, reconcile several contradictory results ever published on the effect of ice water on organisms.

1) Contributions from the Zoological Laboratory, Imperial Fisheries Institute, Tokyo, No. 37.

2) For complete bibliography on ice water cf. T. C. Barnes and Th. L. Jahn: Properties of water of biological interest. Quart. Rev. Biol., 9 (3), 1934.

3) A. Terao and T. Tanaka: Population growth of the water-flea, Moina macrocopa Strauss. Proc. 4 (9), 1928. 
TABle 1. Population growth of Moina macrocopa in either ice or tap water.

\begin{tabular}{|c|c|c|c|c|c|c|c|c|c|c|c|}
\hline \multirow{2}{*}{ Days } & \multirow[t]{2}{*}{ Vial No. } & \multicolumn{5}{|c|}{ Ice water series } & \multicolumn{5}{|c|}{ Tap water series } \\
\hline & & 1 & 2 & 3 & 4 & average & 5 & 6 & 7 & 8 & average \\
\hline \multirow{11}{*}{ June } & 20,1934 & 1 & 1 & 1 & 1 & 1 & 1 & 1 & 1 & 1 & 1 \\
\hline & 21 & 1 & 1 & 1 & 1 & 1 & 1 & 1 & 1 & 1 & 1 \\
\hline & 22 & 1 & 1 & 1 & 1 & 1 & 1 & 1 & 1 & 1 & 1 \\
\hline & 23 & 1 & 1 & 1 & 1 & 1 & 1 & 1 & 1 & 1 & 1 \\
\hline & 24 & 1 & 1 & 1 & 19 & 5.5 & 22 & 2 & 1 & 1 & 6 \\
\hline & 25 & 16 & 16 & 17 & 31 & 20. & 24 & 19 & 20 & 19 & 20.5 \\
\hline & 26 & 19 & 15 & 17 & 23 & 18.5 & 30 & 34 & 44 & 36 & 36. \\
\hline & 27 & 19 & 13 & 9 & 53 & 23.5 & 34 & 38 & 60 & 59 & 47.75 \\
\hline & 28 & 30 & 20 & 9 & 51 & 27.5 & 96 & 59 & 63 & 61 & 69.75 \\
\hline & 29 & 22 & 97 & 24 & 71 & 53.5 & 93 & 65 & 77 & 54 & 72.25 \\
\hline & 30 & 27 & 114 & 46 & 80 & 66.75 & 77 & 78 & 58 & 52 & 66.25 \\
\hline \multirow[t]{4}{*}{ July } & 1 & 25 & 119 & 92 & 120 & 89. & 72 & 70 & 54 & 65 & 65.25 \\
\hline & 2 & 91 & 115 & 131 & 126 & 115.75 & 68 & 87 & 73 & 125 & 88.25 \\
\hline & 3 & 85 & 114 & 128 & 79 & 101.5 & 36 & 69 & 41 & 89 & 58.75 \\
\hline & 4 & 41 & 56 & 90 & 26 & 53.25 & 35 & 34 & 15 & 74 & 39.5 \\
\hline
\end{tabular}

